\title{
Regulation of tumorigenesis in oral epithelial cells by defined reprogramming factors Oct4 and Sox 2
}

\author{
JINGHUA CAI ${ }^{1,2}$, BAOXIA HE $^{3}$, XINMING LI $^{1}$, MINGLEI SUN ${ }^{1}$, ALFRED KING-YIN LAM ${ }^{1,4}$,

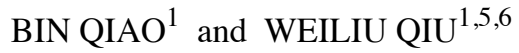

\begin{abstract}
${ }^{1}$ Department of Stomatology, The First Affiliated Hospital of Zhengzhou University, Zhengzhou, Henan 450052; ${ }^{2}$ Henan Key Laboratory of Digestive Organ Transplantation, Zhengzhou, Henan 450052; ${ }^{3}$ Department of Pharmacy, Affiliated Cancer Hospital of Zhengzhou University/Henan Cancer Hospital, Zhengzhou, Henan 450003, P.R. China;

${ }^{4}$ Cancer Molecular Pathology, School of Medicine, Menzies Health Institute Queensland, Griffith University, Gold Coast, Queensland, Australia; ${ }^{5}$ Department of Oral and Maxillofacial Surgery, Ninth People's Hospital, School of Medicine, Shanghai Jiao Tong University, Shanghai 200011;

${ }^{6}$ Shanghai Key Laboratory of Stomatology, Shanghai 200011, P.R. China
\end{abstract}

Received January 27, 2016; Accepted March 1, 2016

DOI: $10.3892 / o r .2016 .4851$

\begin{abstract}
Oct4 and Sox 2 are pluripotent stem cell factors but the interplay between them in tumorigenesis is unclear. The aim of the present study was to investigate the roles of Oct 4 and Sox 2 in the reprogramming of oral cancer stem cells. One or both Oct 4 and Sox 2 were overexpressed in immortalized oral epithelial (hTERT ${ }^{+}-\mathrm{OME}$ ) cells by lentivirus transduction. In addition, Oct 4 and Sox 2 proteins in two oral squamous cell carcinoma cell (OSCC) lines (Cal27 and primary cultured OSCC from a T2N2M0 patient) were individually or combinedly knocked down by shRNA. The results showed that the doubly transduced $\left(\mathrm{Oct} 4^{+} \mathrm{Sox} 2^{+}\right)$cells could trigger neoplasms in immunodeficient mice after lentivirus transduction, but single transduced $\left(\mathrm{Oct} 4^{+}\right.$or Sox $\left.2^{+}\right)$cells had no tumor formation ability. The knockdown Sox $2^{\text {low }}$ and knockdown Oct $4{ }^{\text {low }}$ Sox $2{ }^{\text {low }}$ cells resulted in decreased tumor size in the immunodeficient mice but the single knockdown Oct $4^{\text {low }}$ cancer cells acquired more aggressive xenografts. Our findings suggest that Oct $4^{+}$Sox $2^{+}$cells may be reprogrammed cancer stem cells inducing oral carcinogenesis.
\end{abstract}

\section{Introduction}

There is a subpopulation of cancer cells in tumors that possess the ability to initiate neoplasms and have the property of

Correspondence to: Dr Bin Qiao or Professor Weiliu Qiu, Department of Stomatology, The First Affiliated Hospital of Zhengzhou University, Zhengzhou, Henan 450052, P.R. China

E-mail: qiaobin@zzu.edu.cn

E-mail: qwl@omschina.org.cn

Key words: reprogramming, immortalization, Oct4, Sox2, oral carcinoma self-renewal. These are called cancer stem cells (CSCs) or tumor-initiating cells (TICs) (1). Meantime, somatic cells can be reprogrammed into induced pluripotent stem cells (iPSCs) by defined transduction factors Oct4, Klf4, Sox 2 and c-Myc (OKSM) (2). Incomplete reprogramming is the process by which cells are dedifferentiated by defined factors but do not reach the pluripotent stage (3). However, these partially reprogrammed cells have the ability of tumorigenesis in vivo (4). In addition, the formation of teratomas in immunodeficient mice is one of the properties of identical iPSCs (5). Therefore, there is a parallel pathway between the reprogramming of iPSCs and tumorigenesis. TICs in cancers could be recognized as the products of endogenous reprogramming (6).

Among the defined factors (OKSM), c-Myc is a prooncogene (7) whereas Klf4 could be an oncogene or tumor suppressor (8). In addition, c-Myc can cause genetic instability in iPSC reprogramming but re-expression of Klf4 could counteract the genetic instability in these cells (9). This neutralization guarantees the reprogramming of cells toward the direction to iPSCs but not toward the way to neoplasms. Oct4 and Sox 2 are demonstrated to be good indicators of stem-like capacity (10). Neither Oct4- nor Sox2-knockout mice survive during development of the embryo. Oct4 alone can reprogram neural mouse stem cells into iPSCs in the presence of endogenous Sox 2 expression (11) suggesting that Oct 4 and Sox 2 are indispensable on the road to reprogramming. However, it is not clear, apart from stem cell function, whether Oct 4 or Sox 2 plays a crucial role in the development and progression of human cancer.

In our previous studies, Oct 4 and Sox 2 double-positive cells $\left(\mathrm{Oct} 4^{+} \mathrm{Sox} 2^{+}\right)$were found in the precancerous lesions of the oral mucosa (12), implying that these cells may be undergoing reprogramming into TICs. In addition, in another study, we established an immortalized oral epithelial cell line (hTERT ${ }^{+}$-OME) by human telomerase reverse transcriptase (hTERT) transduction and discovered that this cell line is an ideal model for the study of parallels of reprogramming 
Table I. Culture medium of the cell lines.

Cell line
Culture medium

\author{
hTERT ${ }^{+}$-OME \\ $\mathrm{hTERT}^{+}-\mathrm{O}^{+}-\mathrm{OME}$ \\ hTERT $^{+}-\mathrm{S}^{+}-\mathrm{OME}$ \\ hTERT $^{+}$-OS ${ }^{+}$-OME \\ Cal27, Gca1551 \\ Cal27-O ${ }^{\text {low }}$, Gca1551-O ${ }^{\text {low }}$ \\ Cal27-S ${ }^{\text {low }}$, Gca1551-S ${ }^{\text {low }}$ \\ Cal27-O ${ }^{\text {low }} S^{\text {low }}$, Gca1551-O ${ }^{\text {low }}{ }^{\text {low }}$
}
$\mathrm{A}+200 \mu \mathrm{g} / \mathrm{ml} \mathrm{G} 418$
$\mathrm{A}+200 \mu \mathrm{g} / \mathrm{ml} \mathrm{G} 418+2.5 \mu \mathrm{g} / \mathrm{ml}$ puromycin
$\mathrm{A}+200 \mu \mathrm{g} / \mathrm{ml} \mathrm{G} 418+200 \mu \mathrm{g} / \mathrm{ml}$ hygromycin
$\mathrm{A}+200 \mu \mathrm{g} / \mathrm{ml} \mathrm{G} 418+2.5 \mu \mathrm{g} / \mathrm{ml}$ puromycin $+200 \mu \mathrm{g} / \mathrm{ml}$ hygromycin
A
$\mathrm{A}+2.5 \mu \mathrm{g} / \mathrm{ml}$ puromycin
$\mathrm{A}+2.5 \mu \mathrm{g} / \mathrm{ml}$ puromycin
$\mathrm{A}+2.5 \mu \mathrm{g} / \mathrm{ml}$ puromycin

'A' is a basic medium that is comprised of DMEM/F12 supplemented with $10 \% \mathrm{FBS}, 100 \mu \mathrm{g} / \mathrm{ml}$ penicillin and $100 \mu \mathrm{g} / \mathrm{ml} \mathrm{streptomycin}$. DMEM/F12, Dulbecco's modified Eagle's medium/F12; FBS, fetal bovine serum.

and tumorigenesis (13). In the present study, we proposed that $\mathrm{Oct} 4^{+}$Sox $2^{+}$cells may be reprogrammed TICs inducing oral carcinogenesis, and this hypothesis was studied using a cell model. This hypothesis was examined by detecting the increasing tumorigenesis of Oct4/Sox 2 transduction into the hTERT ${ }^{+}-\mathrm{OME}$ cell line. In addition, two oral squamous cell carcinoma (OSCC) cell lines were used to examine the decreased tumorigenesis by Oct4/Sox 2 knockdown.

\section{Materials and methods}

Cell lines. Twelve cell groups from three cell lines were used in the present study. hTERT ${ }^{+}$-OME is an immortalized cell line created by hTERT gene transduction into primary cultured oral mucosal epithelial (OME) cells (13). Human tongue squamous cell carcinoma cell line (Cal27) was obtained from the American Type Culture Collection (ATCC; Manassas, VA, USA). Gca1551 is a cell line established by primary cultured cells from a 64-year-old man with gingival squamous cell carcinoma with lymph node metastasis (T2N2M0). hTERT ${ }^{+}$$\mathrm{O}^{+}-\mathrm{OME}, \mathrm{hTERT}^{+}-\mathrm{S}^{+}-\mathrm{OME}, \mathrm{hTERT}^{+}-\mathrm{OS}^{+}-\mathrm{OME}, \mathrm{Cal} 27-\mathrm{O}^{\text {low }}$, Cal27-S ${ }^{\text {low }}$, Cal27-O ${ }^{\text {low }} \mathrm{S}^{\text {low }}$, Gca1551-O ${ }^{\text {low }}$, Gca1551-S ${ }^{\text {low }}$ and Gca1551-O ${ }^{\text {low }} \mathrm{S}^{\text {low }}$ cells were derived by our group (see below). Ethical approval was obtained from the Ethics Committee of Zhengzhou University (reference no., 20130523-10-2).

Establishment of Gca1551 cells. Human gingival carcinoma primary tumor samples were obtained within $1 \mathrm{~h}$ after surgery. The tissues were minced with blades into small pieces. These pieces were enzymatically digested using $0.25 \%$ dispase II (Sigma, St. Louis, MO, USA) at $4^{\circ} \mathrm{C}$ overnight. After digestion with $0.25 \%$ trypsin (Sigma) for $10 \mathrm{~min}$ at $37^{\circ} \mathrm{C}$, the tissue was triturated with a pipette and passed through a 200-mm cell strainer. Then, the cells were centrifuged at $300 \mathrm{x} g$ for $5 \mathrm{~min}$, re-suspended in Dulbecco's modified Eagle's medium:nutrient mixture (DMEM/F12) with 10\% fetal bovine serum (FBS), and plated in 6-well plates. Once the cell clones emerged, they were removed by $0.25 \%$ trypsin digestion and cultured in plates. The cells that were not attached after 20 min were collected to purify floating cancer cells from the more rapidly adhering fibroblasts. The collected cells were centrifuged and plated in the new flasks at a density of 1,000 cells $/ \mathrm{cm}^{2}$. The process was repeated several times. The purified cancer cells were acquired and this cell line was named as Gca1551.

Cell culture. All the cell lines were cultured in a basic medium that was comprised of DMEM/F12 supplemented with $10 \%$ FBS, $100 \mathrm{U} / \mathrm{ml}$ penicillin and $100 \mu \mathrm{g} / \mathrm{ml}$ streptomycin (all from Sigma). This basic medium was named as ' $A$ ' in the present study and the culturing details of all cell lines are described in Table I.

In the process of cell reprogramming, hTERT ${ }^{+}-\mathrm{OME}$, hTERT $^{+}-\mathrm{O}^{+}$-OME, hTERT ${ }^{+}-\mathrm{S}^{+}-\mathrm{OME}$ and hTERT $^{+}-\mathrm{OS}^{+}-\mathrm{OME}$ were cultured in TeSR ${ }^{\mathrm{TM}}-\mathrm{E} 7$ and $\mathrm{TeSR}^{\mathrm{TM}}-\mathrm{E} 8$ media (StemCell Technologies, Vancouver, BC, Canada) according to the manufacturer's protocol.

The sphere medium and culture method were the same as previously described (13). Briefly, the medium contained no FBS and was replaced by B27 (serum-free supplement from Invitrogen, Carlsbad, CA, USA). In addition, $20 \mathrm{ng} / \mathrm{ml}$ of epidermal growth factor (Invitrogen) and basic fibroblast growth factor (BD Biosciences, San Jose, CA, USA) were added.

Cell transduction and reprogramming. hTERT ${ }^{+}-\mathrm{OME}$ cells were transduced with lentiviral vectors encoding nuclear reprogramming factors. Briefly, the lentiviral vector plasmids pMXs-hOCT4-GFP (GenePharma, Shanghai, China) and mCMV-hSOX2-mCherry (BioWit Technologies, Shenzhen, China) were introduced into 293T cells using RNAi-Mate transfection reagent. After $48 \mathrm{~h}$, the virus-containing supernatants were passed through a $0.45-\mathrm{mm}$ filter and supplemented with $5 \mathrm{mg} / \mathrm{ml}$ Polybrene. hTERT ${ }^{+}$-OME cells were seeded at $6 \times 10^{5}$ cells/100-mm dish $24 \mathrm{~h}$ before incubation in the virus/Polybrene-containing supernatants for $24 \mathrm{~h}$. The cells were then washed and returned to fresh DMEM/F12 medium. Subsequently, the GFP and mCherry-positive clones were acquired by adding $2.5 \mu \mathrm{g} / \mathrm{ml}$ puromycin and $200 \mu \mathrm{g} / \mathrm{ml}$ hygromycin, respectively. After 7 days, the cells were cultured in ultra-low attachment dishes and the medium was replaced with TeSR ${ }^{\mathrm{TM}}$-E7 medium. After 1 week, the cells were attached on Matrigel (BD Biosciences)-coated plates with TeSR ${ }^{\mathrm{TM}}-\mathrm{E} 7$ medium for 7 days. Then, the culture medium was replaced with $\mathrm{TeSR}^{\mathrm{TM}}-\mathrm{E} 8$ medium for an additional 7 days. After 
transduction and reprogramming, cell colonies were plated in an attachment dish with DMEM/F12 medium supplemented with $10 \%$ FBS. The cells were maintained at $37^{\circ} \mathrm{C}$ in a $5 \% \mathrm{CO}_{2}$ incubator for these days. Thereafter, three cell lines $\left(\mathrm{hTERT}^{+}-\right.$ $\mathrm{O}^{+}$-OME, hTERT ${ }^{+}-\mathrm{S}^{+}-\mathrm{OME}$ and hTERT $\left.^{+}-\mathrm{OS}^{+}-\mathrm{OME}\right)$ were obtained.

Cell transfection and gene knockdown. Two different shRNA sequences were inserted into plasmid vector pVSV-G. 48-72 h after transient transfection. The transfection efficiency was examined using fluorescence microscopy (Axio Observer A1; Carl Zeiss, Jena, Germany) to choose the cells with the most effective transfection. The sequence was then cloned into the pGLV3/H1 and pGLV10/U6 vectors for lentiviral-mediated knockdown of Oct4 and Sox2, respectively. The chosen short hairpin sequence specific for Oct4 was as follows: (5'-CCTTC GCA1551AGCCCTCATTT-3') and Sox2 (5'-GCA1551GACT TCACATGTCCCAGC-3'). These complete vectors were named as LV3 (H1/GFP\&Puro)-Oct4 and LV10 (U6/ RFP\&Puro)-Sox2. The Cal27 and Gca1551 cells were stably transfected with LV3 (H1/GFP\&Puro)-Oct4 and LV10 (U6/ RFP\&Puro)-Sox 2, respectively, according to the manufacturer's protocol (GenePharma). Subsequently, the single GFP- or RFP-positive clones were acquired by adding $2.5 \mu \mathrm{g} / \mathrm{ml}$ puromycin. The double GFP- and RFP-positive clones were selected by sorting using a flow cytometer (Aria II; BD Biosciences). After that, 6 fresh cell lines $\left(\mathrm{Cal} 27-\mathrm{O}^{\text {low }}\right.$, Cal27-S ${ }^{\text {low }}$, Cal27-O ${ }^{\text {low }} \mathrm{S}^{\text {low }}$, Gca1551-O ${ }^{\text {low }}$, Gca1551-S ${ }^{\text {low }}$ and Gca1551-O ${ }^{\text {low }} \mathrm{S}^{\text {low }}$ ) were formed. All cells were tested for Oct4 and Sox 2 protein expression by western blotting.

Western blotting. Eight cell lines (Cal27, Cal27-O ${ }^{\text {low }}, \mathrm{Cal} 27-\mathrm{S}^{\text {low }}$, Ca127-O ${ }^{\text {low }} \mathrm{S}^{\text {low }}$, Gca1551, Gca1551-O ${ }^{\text {low }}$, Gca1551-S ${ }^{\text {low }}$ and Gca1551-O ${ }^{\text {low }}{ }^{\text {low }}$ ) were analyzed by western blotting. The total protein was extracted from the cultured cells using lysis buffer (Bio-Rad, Hercules, CA, USA). Proteins (40 $\mu \mathrm{g}$ ) were subjected to sodium dodecyl sulfate-polyacrylamide gel electrophoresis (SDS-PAGE) with $10 \%$ polyacrylamide gels and transferred to polyvinylidene fluoride membranes (Bio-Rad). The membranes were then incubated with primary antibodies overnight at $4^{\circ} \mathrm{C}$, washed twice and incubated with horseradish peroxidase-conjugated secondary antibody (Bio-Rad) for $2 \mathrm{~h}$ at room temperature. Subsequently, the protein bands were detected by enhanced chemiluminescence, visualized using a VersaDoc-MP Imaging system (Bio-Rad). The antibodies used were goat anti-rabbit-Oct4, goat anti-rabbit-Sox 2 (both from Stemgent, San Diego, CA, USA) and goat anti-mouse-GAPDH (Boster, Wuhan, China). The concentrations used were 1:500 (Oct4), 1:500 (Sox2) and 1:1,000 (GAPDH), respectively.

In vivo tumor formation assay. One hundred and twenty 5-week-old non-obese diabetic severe combined immunodeficiency (NOD/SCID) mice (16-18 g, all males) (Vital River Laboratories, Beijing, China) were divided into 12 groups, with 10 mice in each group. Twelve groups of cells were washed twice with antibiotic- and serum-free cell culture medium and finally resuspended in $0.1 \mathrm{ml}$ of serum-free culture medium. The cell suspension was then mixed with an equal volume of Matrigel (BD Biosciences) and injected subcutaneously into the mice. The tumors that formed were surgically removed after
21 days. All the xenografts of oral squamous cell carcinoma were weighed. Representative tumor tissues were fixed in 3\% formalin, embedded in paraffin wax and sectioned at a thickness of $10 \mu \mathrm{m}$. The sections were stained with hematoxylin and eosin (H\&E) for pathological examination, or processed for immunohistochemical analysis. The experiments were carried out in accordance with the guidelines issued by the Ethics Committee of Zhengzhou University.

Immunohistochemistry of tumor tissue sections. For immunohistochemistry, paraffin-embedded tissue sections were removed of paraffin in xylene, and dehydrated in alcohol. Afterwards, the sections were subjected to antigen retrieval with a steam pressure cooker $\left(120^{\circ} \mathrm{C}, 5 \mathrm{~min}\right)$ in citrate buffer (pH 6.0), washed with phosphate-buffered saline (PBS) and then blocked with 5\% goat serum. Primary antibodies were diluted in $0.1 \%$ bovine serum albumin (BSA) and incubated with the sections overnight at $4^{\circ} \mathrm{C}$. After incubation with the secondary antibody at room temperature for $60 \mathrm{~min}$, the sections were stained with SP link detection kits (ZSGB-BIO, Beijing, China) according to the manufacturer's instructions. The primary antibodies used in the present study were as follows: goat anti-rabbit-Oct4 (1:200), goat anti-rabbit-Sox 2 (1:200) (both from Stemgent), goat anti-rabbit-CK5 (1:100), goat anti-rabbit-CK19 (1:100), goat anti-rabbit-vimentin (1:100), goat anti-rabbit-Ki-67 (1:100), goat anti rabbit-CD31 (1:100) and goat anti rabbit-calponin (1:100) (all from Bioss, Beijing, China).

Statistical analysis. All values for tumors weight are presented as mean \pm standard deviation. Comparisons between four groups of two cell lines were performed by one-way ANOVA. The significance level was assigned at $\mathrm{P}<0.05$. The statistical tests were performed with the program, Statistical Package for Social Sciences (IBM SPSS 22.0; IBM SPSS, Armonk, NY, USA).

\section{Results}

Reprogramming of human immortalized oral mucosal epithelial cells by defined reprogramming factors. The lentiviral-mediated introduction of Oct4 and Sox 2 (both or individual) into hTERT $^{+}-\mathrm{OME}$ cells, followed by a series of reprogramming steps (Fig. 1), gave rise to the expression of Oct 4 and Sox 2 proteins in the nuclei of the cells after 28 days. The entire process was recorded by fluorescence microscopy (Fig. 2).

Tumorigenesis of hTERT $T^{+}-\mathrm{OS}^{+}-\mathrm{OME}$ cells in vivo. The ability of hTERT ${ }^{+}-\mathrm{OS}^{+}-\mathrm{OME}$ cells to form tumors in the xenograft model was assessed by injection of hTERT ${ }^{+}$-OME, hTERT $^{+}-\mathrm{O}^{+}$-OME, hTERT ${ }^{+}-\mathrm{S}^{+}$-OME and hTERT $^{+}-\mathrm{OS}^{+}-\mathrm{OME}$ cells subcutaneously into NOD/SCID mice, respectively and then the tumors were monitored for 21 days. As a result, only the hTERT ${ }^{+}-\mathrm{OS}^{+}-\mathrm{OME}$ group of cells was able to initiate tumor formation in the mice (Fig. 3A). Histological examinations of the tumors revealed that hTERT ${ }^{+}-\mathrm{OS}^{+}-\mathrm{OME}$ cells produced tumors with local invasion (Fig. 3B). Immunohistochemical studies demonstrated that the tumors had differentiation from epithelial cells (CK5- and CK19-positive) with mesenchymal 


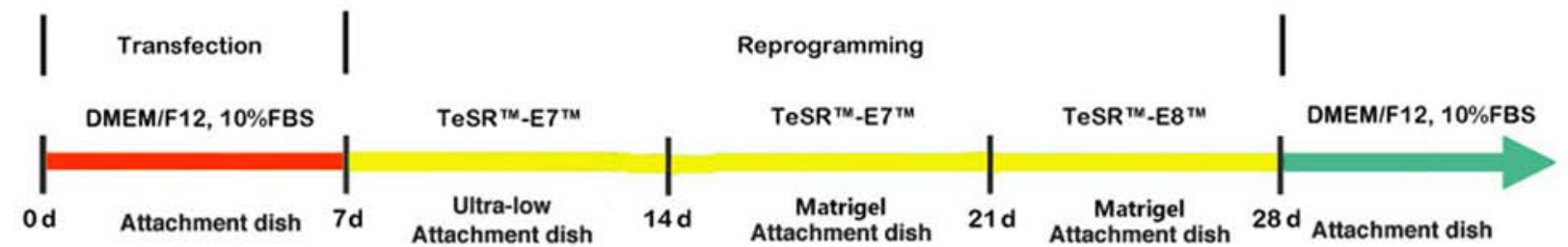

Figure 1. Experimental scheme for the reprogramming of hTERT ${ }^{+}$-OME cells. On the 7th day of transduction, the cells were cultured in ultra-low attachment dishes and the medium was replaced with TeSR ${ }^{\mathrm{TM}}$-E7 medium. On the 14th day, the cells were attached to Matrigel (BD Biosciences)-coated plates with TeSR ${ }^{\mathrm{TM}}$-E7 medium. On the 21st day, the culture medium was changed to TeSR ${ }^{\mathrm{TM}}$-E8 medium. On the 28th day, the transduction and reprogramming was completed, and cell colonies were plated in an attachment dish with DMEM/F12 medium supplemented with 10\% FBS.
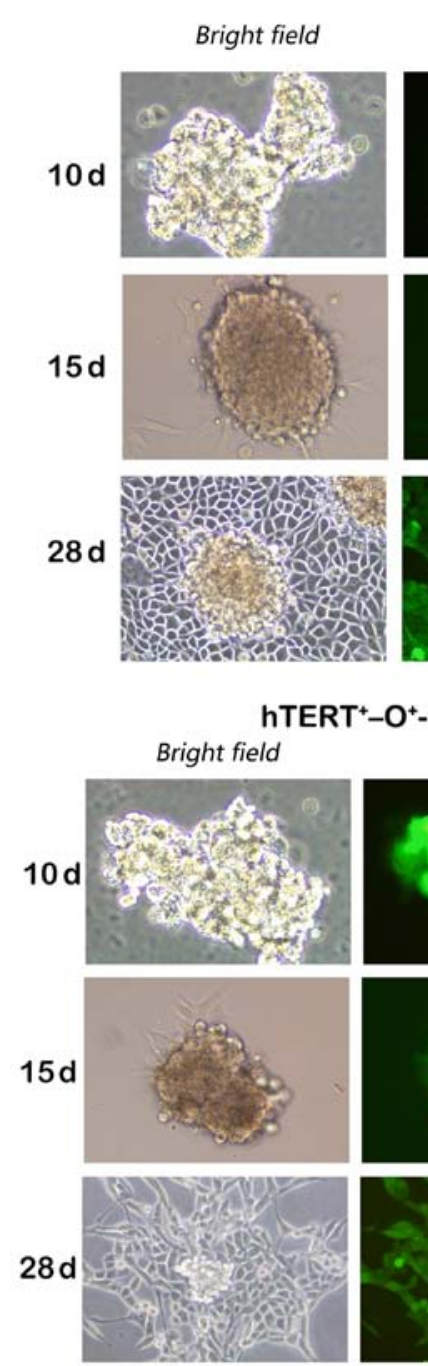

hTERT+-OS+-OME
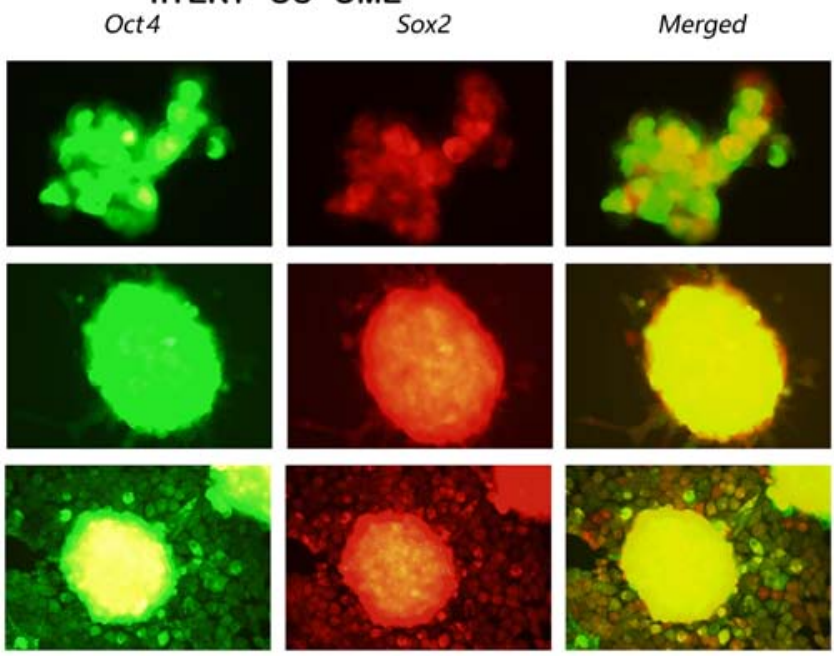

hTERT+-S+-OME
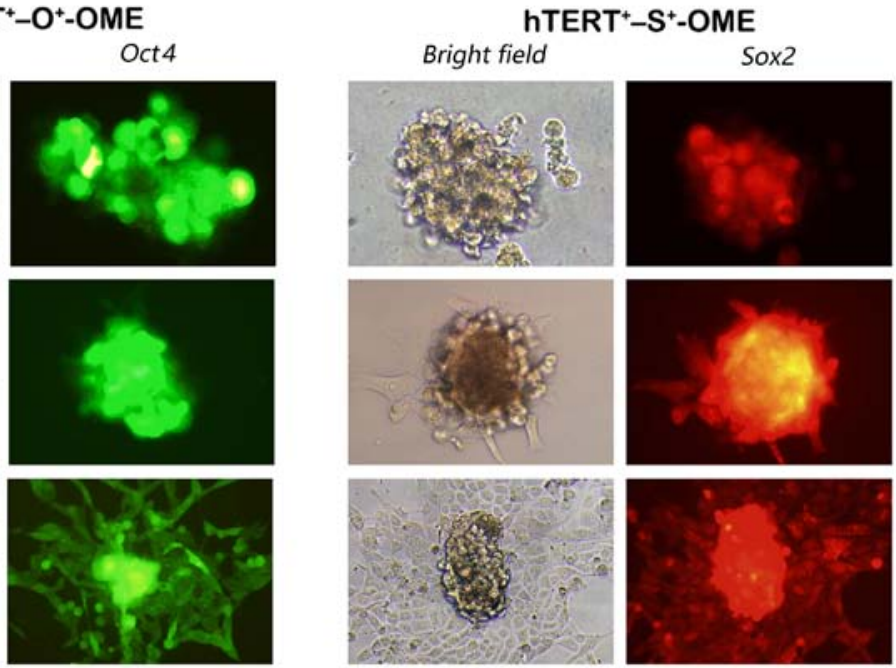
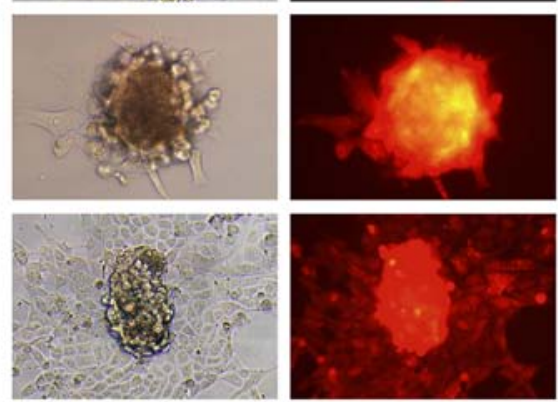

Figure 2. Three types of cells (hTERT ${ }^{+}-\mathrm{O}^{+}-\mathrm{OME}, \mathrm{hTERT}^{+}-\mathrm{S}^{+}-\mathrm{OME}$ and hTERT ${ }^{+}-\mathrm{OS}^{+}-\mathrm{OME}$ ) with images captured by fluorescence microscope. The iPSC-like colonies were observed in the three types of cells when they were cultured on Matrigel-coated flasks in the reprogramming process. After 21 days of reprogramming, all the cells had nuclear expression of Oct 4 and Sox 2 . hTERT ${ }^{+}-\mathrm{OS}^{+}-\mathrm{OME}$ cells demonstrated epitheloid like morphology while some hTERT ${ }^{+}-\mathrm{O}^{+}-\mathrm{OME}$ and $\mathrm{hTERT}^{+}-\mathrm{S}^{+}-\mathrm{OME}$ cells were spindle in shape. Scale bar, $200 \mu \mathrm{m}$.

properties (vimentin-positive). In addition, we detected that Oct 4 and Sox 2 transduced into the hTERT ${ }^{+}-\mathrm{OS}^{+}-\mathrm{OME}$ cells were positively expressed in the xenografts (Fig. 3B).

Tumorigenesis of shRNA-mediated OSCC cells in vivo. Western blot analysis showed that the expression levels of
Oct 4 and Sox 2 were effectively altered by shRNA transfection in the Cal27 and Gca1551 cells. Downregulation of Sox 2 by shRNA led to the slight downregulation or no change of Oct4 expression, while shRNA-mediated repression of Oct 4 induced the upregulation of Sox 2 expression (Fig. 4). In the xenograft model, Sox $2^{\text {low }}$ and Oct $4{ }^{\text {low }}$ Sox $2^{\text {low }}$ cells decreased the size 
A
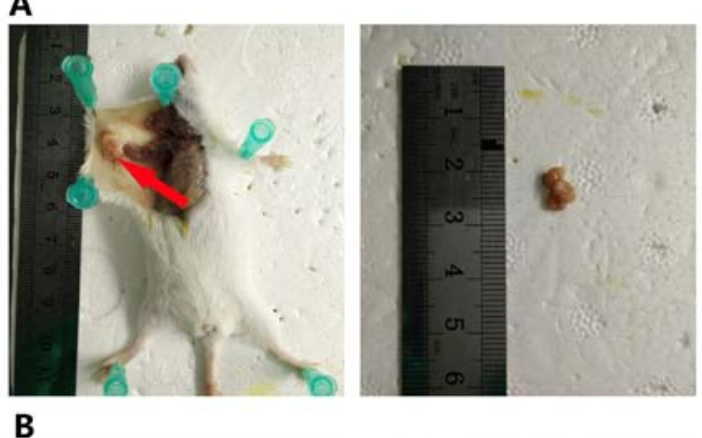

B
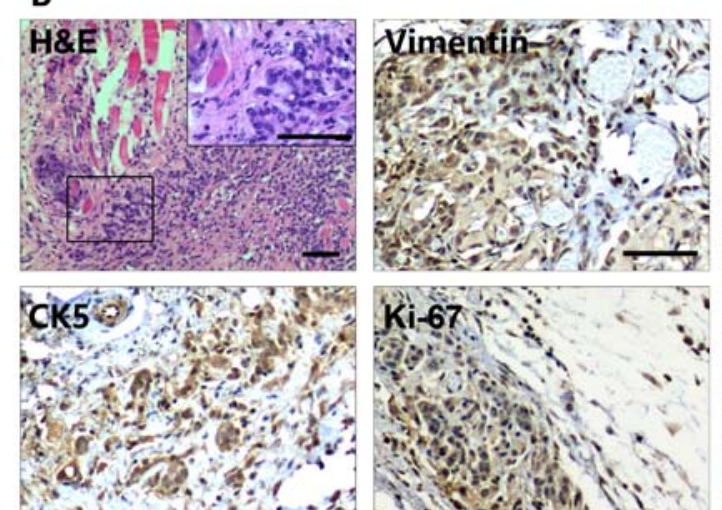

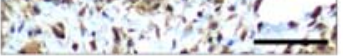
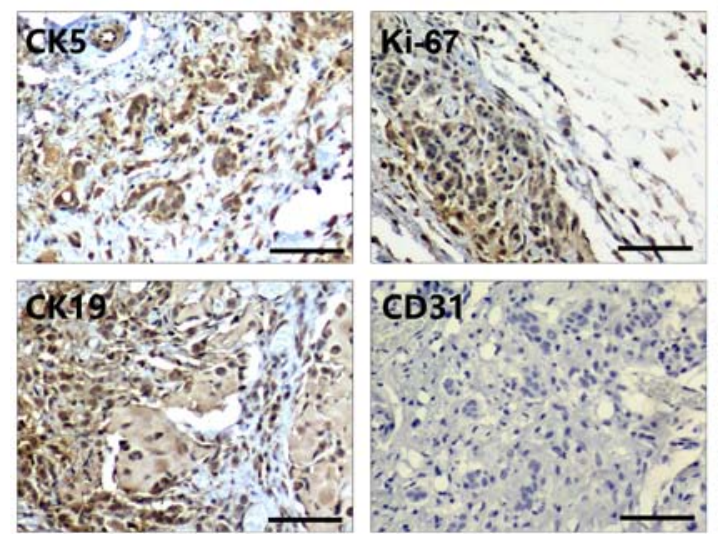
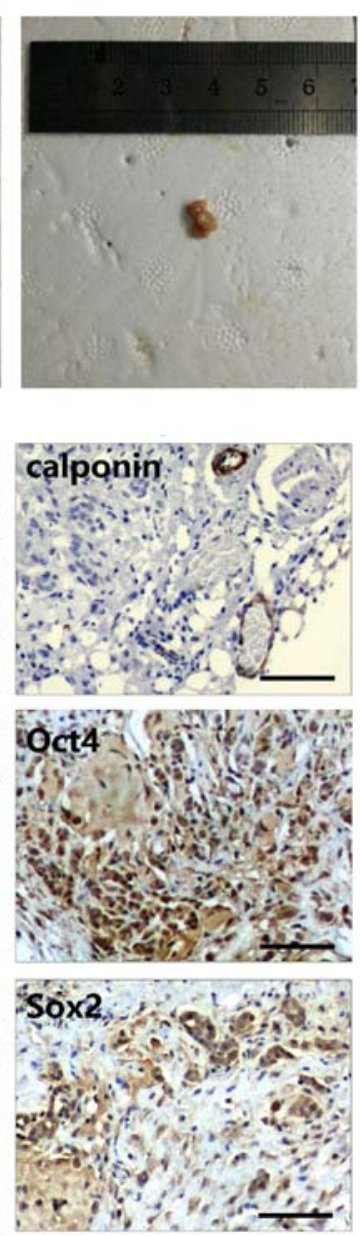

Figure 3. hTERT ${ }^{+}$OS $^{+}-\mathrm{OME}$ cells form tumors in vivo and hematoxylin and eosin (H\&E) staining and immunohistochemical analysis of a neoplasm derived from hTERT ${ }^{+}-\mathrm{OS}^{+}-\mathrm{OME}^{+}$cells. (A) A representative case shows a neoplasm initiated by hTERT $\mathrm{T}^{+}-\mathrm{OS}^{+}-\mathrm{OME}$ cells subcutaneously injected into a mouse. (B) Histopathological examination showed that the tumor cells were noted invading into the skeletal muscles (H\&E). In addition, the tumor cells were positive for cytokeratins CK5 and CK19 (epithelial markers), vimentin (mesenchymal marker, positive), Ki-67 (proliferation activity marker) and Oct4 and Sox2. They were negative for CD31 (endothelial marker) and calponin (smooth muscle marker). Scale bar, $200 \mu \mathrm{m}$.

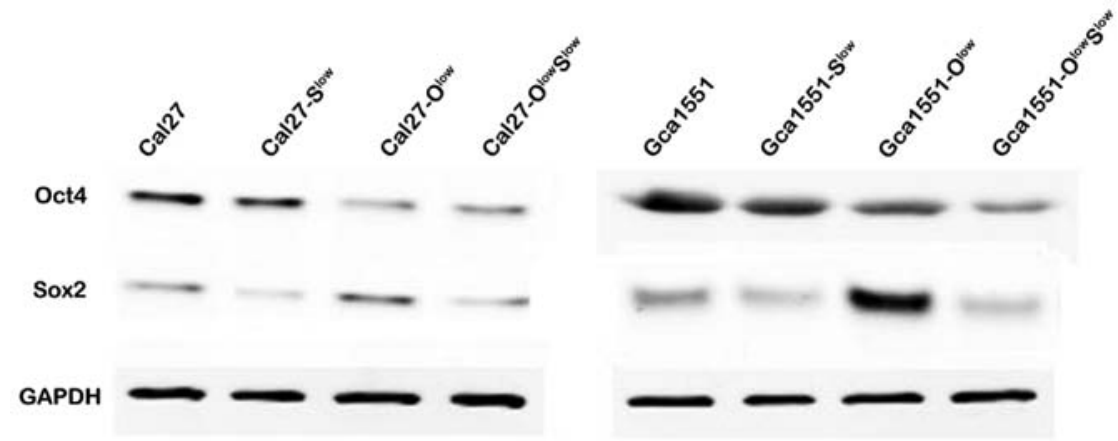

Figure 4. Levels of Oct4 and Sox 2 were determined by western blot analyses after shRNA-mediated knockdown. Oct4, Sox 2 and GAPDH were strongly expressed in controls (Cal27 and Gca1551). Oct4 level was markedly decreased in Cal27-O ${ }^{\text {low }}, \mathrm{Ca} 27-\mathrm{O}^{\text {low }} \mathrm{S}^{\text {low }}$, Gca1551- $\mathrm{O}^{\text {low }}$ and $\mathrm{Gca} 1551-\mathrm{O}^{\text {low }} \mathrm{S}^{\text {low }}$ cells. In

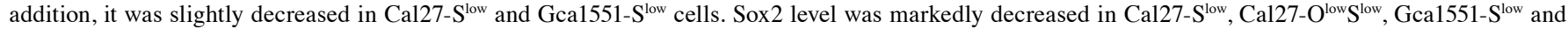
Gca1551-O ${ }^{\text {low }} \mathrm{S}^{\text {low }}$ cells. However, it was apparently increased in Cal27-O $\mathrm{O}^{\text {low }}$ and Gca1551-O $\mathrm{O}^{\text {low }}$ cells.

of tumors in the immunodeficient mice equally. In contrast, the single knockdown Oct4 $4^{\text {low }}$ cancer cells had increased tumor size when compared to the untreated cells (Fig. 5). The weight of each group of tumors was measured and the results are detailed in graphical representation (Fig. 6A).
Moreover, the histological examinations demonstrated that Sox $2^{\text {low }}$ or Oct $4^{\text {low }}$ Sox $2^{\text {low }}$ cells caused low histological grade carcinoma in the xenografts, while the Oct $4^{\text {low }}$ cancer cells formed more aggressive xenografts comprised of high grade carcinoma (Fig. 6B). 

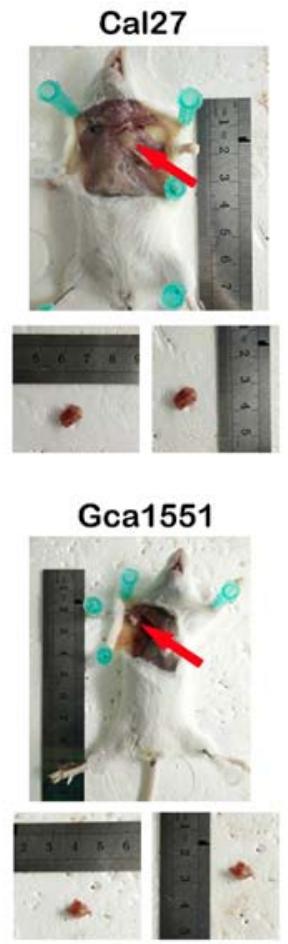

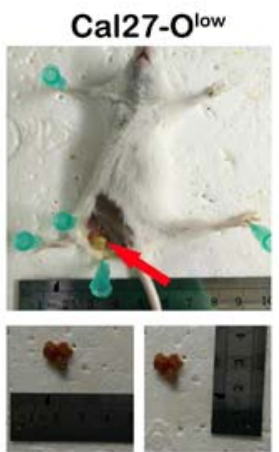

Gca1551-O'low

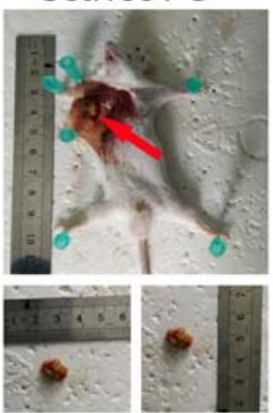

Cal27-S low

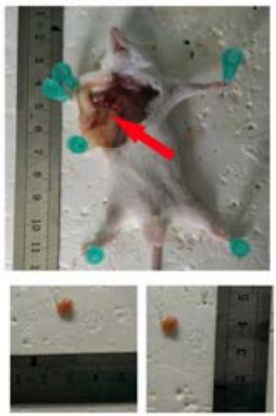

Gca1551-S low

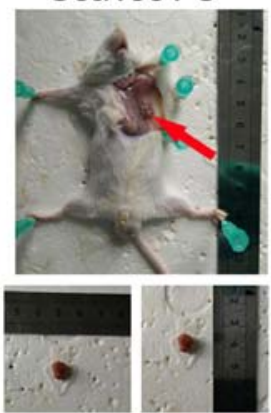

Cal27-O ${ }^{\text {low }}{ }^{\text {low }}$

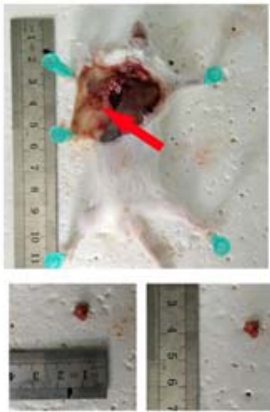

Gca1551-O ${ }^{\text {low }} \mathbf{S}^{\text {low }}$

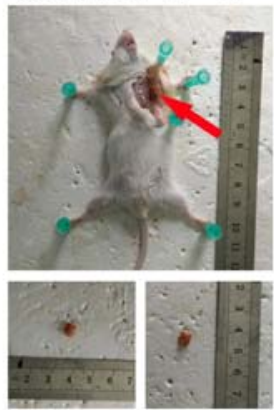

Figure 5. Gross specimens of shRNA-mediated OSCC cells in vivo. Compared to untreated cells, Cal27-O ${ }^{\text {low }}$ and Gca1551-O ${ }^{\text {low }}$ cells acquired larger xenografts while Ca127-S ${ }^{\text {low }}$, Cal27- $\mathrm{O}^{\text {low }} \mathrm{S}^{\text {low }}$, Gca1551-S $\mathrm{S}^{\text {low }}$ and Gca1551- ${ }^{\text {low }} \mathrm{S}^{\text {low }}$ cells initiated smaller xenografts. It is worth noting that the double knockdown cells $\left(\mathrm{O}^{\text {low }} \mathrm{S}^{\text {low }}\right)$ did not exhibit stronger tumor inhibition than the single knockdown cells $\left(\mathrm{S}^{\mathrm{low}}\right)$.

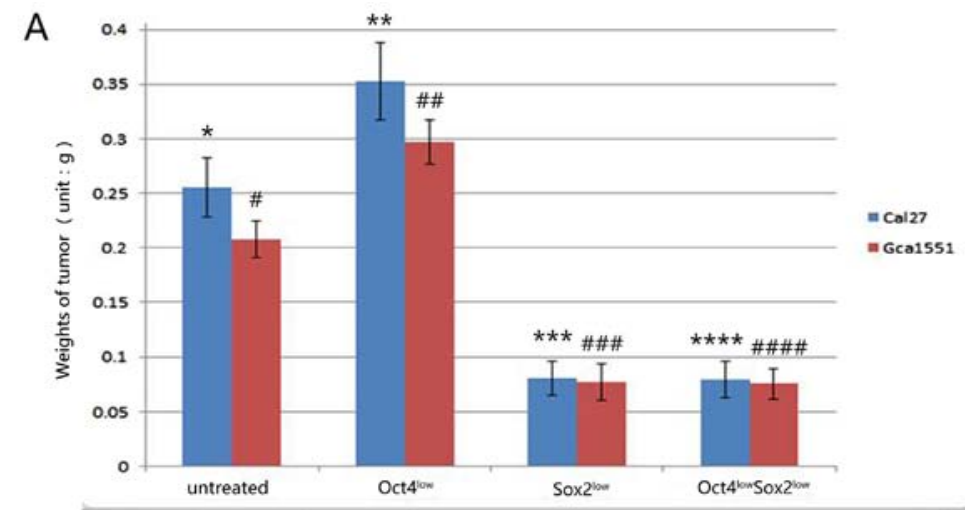

\section{B}

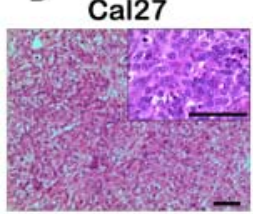

Cal27-O low

Cal27-S ${ }^{\text {low }}$

Cal27-O ${ }^{\text {low }} \mathbf{S}^{\text {low }}$
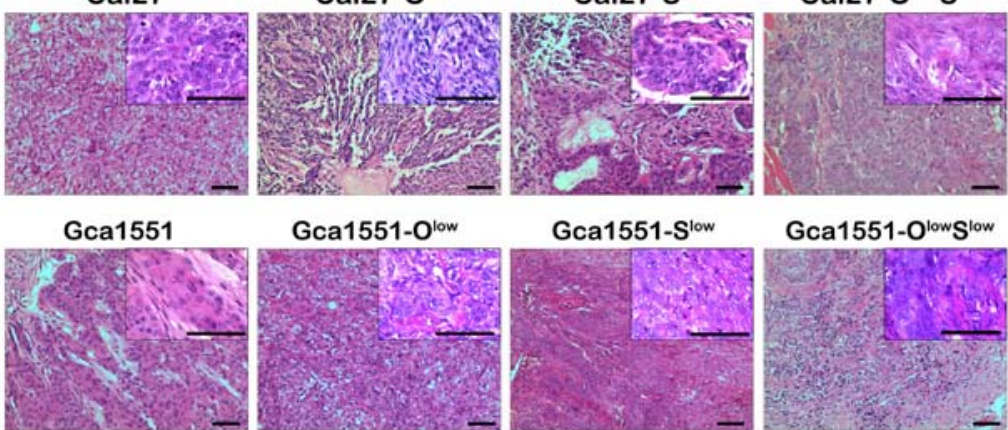

Gca1551-O'ow

Gca1551-S
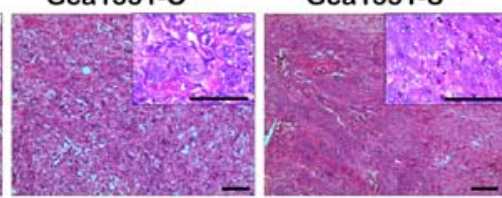

Gca1551-O'low $\mathbf{S}^{\text {low }}$

Figure 6. The average weights of each group of tumors and H\&E staining showing the pathological differentiation in the representative human OSCC xenografts. (A) The histogram shows the weight changes of tumors in each group $\left({ }^{*}\right.$ vs. ${ }^{* *}$ or ${ }^{*}$ vs. ${ }^{* * *}$ or ${ }^{*}$ vs. $\left.{ }^{* * * *}\right)$ p $<0.05 ;{ }^{* * * *}$ vs. ${ }^{* * * * *}$ p $>0.05$; $\left({ }^{\#}\right.$ vs. ${ }^{\# \#}$ or ${ }^{\#}$ vs. ${ }^{\# \# \#}$ or

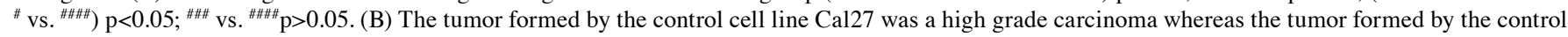
cell line Gca1551 was a low grade carcinoma. After Oct4 knockdown, the tumor in the xenografts became dedifferentiated. The tumor in the Cal27-O ${ }^{\text {low }}$ xenograft became more dedifferentiated and the tumor in Gca1551-O ${ }^{\text {low }}$ became a high grade carcinoma. After Sox 2 knockdown, the xenografts became better differentiated in the Ca127-derived xenograft. The tumor from the Cal27-S ${ }^{\text {low }}$ xenograft was of lower grade when compared to the control. In the tumor from Gca1551-S ${ }^{\text {low }}$ xenograft, the tumor appeared to be similar to the control. After Sox 2 and Oct4 knockdown, in the xenografts, the effect was similar to the Sox 2 single knockdown. Thus, the histology of the tumor in Cal27- $\mathrm{O}^{\text {low }} \mathrm{S}^{\text {low }}$ was of low grade. The histology of the tumor in Gca1551- $\mathrm{O}^{\text {low }} \mathrm{S}^{\text {low }}$ was also of low grade. Scale bar, $200 \mu \mathrm{m}$. 


\section{Discussion}

The ambiguous origin of tumor-initiating cells (TICs) makes these cells difficult to be eliminated by conventional adjuvant therapy and induces tumor relapse and metastasis. One of the possible origins of TICs is from adult stem cells since adult stem cells can survive for several years with accumulation of epigenetic and genetic alterations (14). In contrast, the origin of induced pluripotent stem cells that are reprogrammed from somatic cells is under debate. It is argued that these parental reprogrammed cells actually are adult stem cells which reside in tissues when the samples are collected for primary culture (15). Adult stem cells own limited differentiation behavior in contrast to embryonic stem cells. They may be the residues of the embryo in the body since various adult stem cells express the same molecules that are found in embryonic stem cells (16). It is possible that there is a common origin of adult stem cells, TICs and iPSCs. Cell reprogramming between these cells may be a potential way to tumorigenesis.

Nishi et al acquired cells with malignant stem cell properties from MCF-10A mammary epithelial cells by OSKM transduction (17). Both MCF-10A (18) and hTERT ${ }^{+}$-OME cells were non-tumorigenic immortalized epithelial cells. In contrast to the findings of Nishi $\mathrm{et} \mathrm{al}$, the present study showed that hTERT ${ }^{+}-\mathrm{OS}^{+}-\mathrm{OME}$ cells initiated tumors in a mouse model but not invasive cancer. A possible explanation is that factors Klf4 and c-Myc control the property of the neoplasm but factors Oct 4 and Sox 2 play a pivotal role in neoplasm derivation. This viewpoint is supported by another independent study that reported that dysplastic epithelial cells (pre-cancer) were observed in several organs in one mouse when Oct4 was forciby expressed in gene-editing mice (19).

Oct4 expresses its Oct4B variant in the cytoplasm of embryonic stem cells and numerous somatic cells without stem cell function (20). Sox 2 plays the role of the cytoskeleton when it is expressed in the cytoplasm (21). Oct4 and Sox 2 expressed in the cytoplasm cannot play a role of reprogramming since chromatin remodeling occurs in cell nuclei. The cellular nuclear translocation of Oct 4 was noted when hTERT ${ }^{+}$-OME cells were cultured in a 3-dimentional environment as we previously demonstrated (13). However, neither hTERT ${ }^{+}-\mathrm{O}^{+}$-OME nor $\mathrm{hTERT}^{+}-\mathrm{S}^{+}$-OME cells triggered tumor formation in immunodeficient mice although the hTERT $^{+}-\mathrm{S}^{+}$-OME cells particularly underwent 3 -dimentional culture to acquire spontaneous Oct 4 nuclear expression in the present study. These findings showed that hTERT ${ }^{+}$-OME cells cannot move into reprogramming spontaneously without exogenous Oct4 gene transduction. In pathological examination, we found that human oral precancerous lesions cannot induce xenograft tumors in immunodeficient mice despite the fact that $\operatorname{Oct} 4^{+}$Sox $2^{+}$profile cells were observed in oral lichen planus and oral leukoplakia $(12,22)$. This raised the question of why hTERT ${ }^{+} \mathrm{OS}^{+}-\mathrm{OME}$ cells have the ability of tumorigenesis in the present study. Arnold et al reported that Sox $2^{+}$adult stem cells in several epithelia originate from fetal Sox $2^{+}$tissue progenitors by developmental fate mapping (23). This implies that Sox $2^{+}$adult stem cells, not Oct $4^{+}$cells, in normal epithelial cells of oral mucosa may be residues of the embryo. The hTERT ${ }^{+}-\mathrm{S}^{+}$-OME cells cultured in suspension to acquire Oct 4 nuclear expression resembles a situation in which specific Sox $2^{+}$adult stem cells in tissues accumulate active Oct4 variant with nuclear expression. This may occur when there are changes in the surrounding microenvironment, such as an inflammatory reaction, to form Oct $4^{+}$Sox $2^{+}$profile cells in vivo. Only by transducing exogenous Oct 4 into cells in vitro, can the genome be reprogrammed into the direction of neoplasm.

Oct4 is known to bind in partnership with Sox2 to form Oct-Sox enhancers. Downregulation of Sox 2 causes downregulation of Oct4 activators and upregulation of Oct4 repressors, resulting in the gradual downregulation of Sox 2 (24). In melanoma cells, RNA interference-mediated knockdown of Oct4 led to diminished TIC phenotypes (25). Sox 2 knockdown delayed tumor formation in xenograft tumor initiation models of breast cancer (26). An independent study demonstrated that when Sox 2 was elevated $\sim 2$-fold in embryonic stem cells, the levels of Oct4 did not change (27). Notably, another independent study indicated that once the level of Oct4 in embryonic stem cells was increased, the Sox 2 level began to decrease at the RNA level (28). In the present study, by knocking down the expression of Oct4 and Sox 2 in Cal27 and Gca1551 OSCC cells, Sox $2^{\text {low }}$ and Oct $4^{\text {low }}$ Sox $2^{\text {low }}$ cells exhibited equal tumor inhibition in vivo and low grade carcinoma in the xenografts. In contrast, the single knockdown Oct $4^{\text {low }}$ cancer cells increased tumor size in mouse models and the cancer cells formed higher grade carcinoma in xenografts than the untreated cells. Our results indicated that, at least at the protein level, RNA interference of Sox 2 may suppress Sox 2 and further Oct 4 expression via a positive loop, while downregulation of Oct 4 could upregulate Sox 2 expression via negative feedback in Oct $4^{\text {low }}$ cancer cells. An explanation is that elevating or decreasing either Sox 2 or Oct4 in specific cells changes the critical ratio between these two master regulators. This imbalance then induces the cell differentiation in embryonic stem cells and dedifferentiation in tumor cells. However, this hypothesis has not been well studied in the scientific world. Since Sox $2^{+}$cells were noted in primary sites of oral cancer with lymph node metastasis in our previous study (22), combined with these findings discovered in the present study, it is suggested that Sox 2 inhibition, not Oct 4 , should be a therapeutic target for oral cancer. In addition, Oct4 may have a dual-character (oncogene or tumor suppressor) in OSCC development. Exploring this hypothesis is the subject of further study.

To conclude, somatic cells can be reprogrammed into TICs as represented by the hTERT ${ }^{+}-\mathrm{OS}^{+}-\mathrm{OME}$ cells in the present study. In addition, oral carcinogenesis may be derived from Oct $4^{+}$Sox $2^{+}$reprogrammed TICs in which Oct 4 plays the role of derivation while Sox 2 plays the role of stem cell property. In the absence of Oct 4 expression, neoplasms could not be initiated from normal tissues. Without Sox 2 expression, the neoplastic cells could not be self-renewed to maintain tumor growth. By studying these processes of induced reprogramming, novel insights into the origins and control of epigenetic alterations in human neoplasms may be achieved.

\section{Acknowledgements}

The present study was supported by the National Natural Science Foundation of China (grant no. 81200796), the 
Zhengzhou Department for Science and Technology (grant no. 131PPTGG409-20), and funding from the Youth Foundation of The First Affiliated Hospital of Zhengzhou University.

\section{References}

1. González-Moles MA, Scully C, Ruiz-Ávila I and PlazaCampillo JJ: The cancer stem cell hypothesis applied to oral carcinoma. Oral Oncol 49: 738-746, 2013.

2. Takahashi $\mathrm{K}$ and Yamanaka S: Induction of pluripotent stem cells from mouse embryonic and adult fibroblast cultures by defined factors. Cell 126: 663-676, 2006

3. Mattout A, Biran A and Meshorer E: Global epigenetic changes during somatic cell reprogramming to iPS cells. J Mol Cell Biol 3: 341-350, 2011.

4. Ohnishi K, Semi K, Yamamoto T, Shimizu M, Tanaka A, Mitsunaga K, Okita K, Osafune K, Arioka Y, Maeda T, et al: Premature termination of reprogramming in vivo leads to cancer development through altered epigenetic regulation. Cell 156: 663-677, 2014

5. Yan X, Qin H, Qu C, Tuan RS, Shi S and Huang GT: iPS cells reprogrammed from human mesenchymal-like stem/progenitor cells of dental tissue origin. Stem Cells Dev 19: 469-480, 2010.

6. Hobbs RM and Polo JM: Reprogramming can be a transforming experience. Cell Stem Cell 14: 269-271, 2014.

7. Adhikary S and Eilers M: Transcriptional regulation and transformation by Myc proteins. Nat Rev Mol Cell Biol 6: 635-645, 2005.

8. El-Karim EA, Hagos EG, Ghaleb AM, Yu B and Yang VW: Krüppel-like factor 4 regulates genetic stability in mouse embryonic fibroblasts. Mol Cancer 12: 89, 2013.

9. Yamanaka S: Pluripotency and nuclear reprogramming. Philos Trans R Soc Lond B Biol Sci 363: 2079-2087, 2008

10. Lin SL: Concise review: Deciphering the mechanism behind induced pluripotent stem cell generation. Stem Cells 29: $1645-1649,2011$.

11. Kim JB, Sebastiano V, Wu G, Araúzo-Bravo MJ, Sasse P, Gentile L, Ko K, Ruau D, Ehrich M, van den Boom D, et al: Oct4-induced pluripotency in adult neural stem cells. Cell 136: 411-419, 2009.

12. Islam F, Qiao B, Smith RA, Gopalan V and Lam AK: Cancer stem cell: Fundamental experimental pathological concepts and updates. Exp Mol Pathol 98: 184-191, 2015.

13. Qiao B, Gopalan V, Chen Z, Smith RA, Tao Q and Lam AK: Epithelial-mesenchymal transition and mesenchymal-epithelial transition are essential for the acquisition of stem cell properties in hTERT-immortalised oral epithelial cells. Biol Cell 104 476-489, 2012.

14. Smalley M and Ashworth A: Stem cells and breast cancer: A field in transit. Nat Rev Cancer 3: 832-844, 2003.
15. Sugii S, Kida Y, Berggren WT and Evans RM: Feeder-dependent and feeder-independent iPS cell derivation from human and mouse adipose stem cells. Nat Protoc 6: 346-358, 2011.

16. Ellis P, Fagan BM, Magness ST, Hutton S, Taranova O, Hayashi S, McMahon A, Rao M and Pevny L: SOX2, a persistent marker for multipotential neural stem cells derived from embryonic stem cells, the embryo or the adult. Dev Neurosci 26: 148-165, 2004.

17. Nishi M, Sakai Y, Akutsu H, Nagashima Y, Quinn G, Masui S, Kimura H, Perrem K, Umezawa A, Yamamoto N, et al: Induction of cells with cancer stem cell properties from nontumorigenic human mammary epithelial cells by defined reprogramming factors. Oncogene 33: 643-652, 2014.

18. Soule HD, Maloney TM, Wolman SR, Peterson WD Jr, Brenz R, McGrath CM, Russo J, Pauley RJ, Jones RF and Brooks SC: Isolation and characterization of a spontaneously immortalized human breast epithelial cell line, MCF-10. Cancer Res 50: 6075-6086, 1990.

19. Hochedlinger K, Yamada Y, Beard C and Jaenisch R: Ectopic expression of $O c t-4$ blocks progenitor-cell differentiation and causes dysplasia in epithelial tissues. Cell 121: 465-477, 2005.

20. Guo CL, Liu L, Jia YD, Zhao XY, Zhou Q and Wang L: A novel variant of Oct3/4 gene in mouse embryonic stem cells. Stem Cell Res 9: 69-76, 2012.

21. Liu L, Wei X, Ling J, Wu L and Xiao Y: Expression pattern of Oct-4, Sox2, and c-Myc in the primary culture of human dental pulp derived cells. J Endod 37: 466-472, 2011.

22. Qiao B, He B, Cai J and Yang W: The expression profile of Oct4 and Sox 2 in the carcinogenesis of oral mucosa. Int J Clin Exp Pathol 7: 28-37, 2013.

23. Arnold K, Sarkar A, Yram MA, Polo JM, Bronson R, Sengupta S, Seandel M, Geijsen N and Hochedlinger K: Sox $2^{+}$adult stem and progenitor cells are important for tissue regeneration and survival of mice. Cell Stem Cell 9: 317-329, 2011.

24. Masui S, Nakatake Y, Toyooka Y, Shimosato D, Yagi R, Takahashi K, Okochi H, Okuda A, Matoba R, Sharov AA, et al: Pluripotency governed by Sox 2 via regulation of Oct3/4 expression in mouse embryonic stem cells. Nat Cell Biol 9: 625-635, 2007.

25. Kumar SM, Liu S, Lu H, Zhang H, Zhang PJ, Gimotty PA, Guerra M, Guo W and Xu X: Acquired cancer stem cell phenotypes through Oct4-mediated dedifferentiation. Oncogene 31: 4898-4911, 2012.

26. Leis O, Eguiara A, Lopez-Arribillaga E, Alberdi MJ, HernandezGarcia S, Elorriaga K, Pandiella A, Rezola R and Martin AG: Sox 2 expression in breast tumours and activation in breast cancer stem cells. Oncogene 31: 1354-1365, 2012.

27. Kopp JL, Ormsbee BD, Desler M and Rizzino A: Small increases in the level of Sox 2 trigger the differentiation of mouse embryonic stem cells. Stem Cells 26: 903-911, 2008.

28. Niwa H, Miyazaki J and Smith AG: Quantitative expression of Oct-3/4 defines differentiation, dedifferentiation or self-renewal of ES cells. Nat Genet 24: 372-376, 2000. 